\title{
The Impact of Noise in the Environment on the Acoustic Assessment of Green Houses
}

\author{
Artur Nowoświat, Jan Ślusarek, Rafał Żuchowski and Bartłomiej Pudełko \\ Silesian University of Technology, Faculty of Civil Engineering, 44-190 Gliwice, Poland.
}

(Received 13 October 2017; accepted 13 December 2017)

\begin{abstract}
In various green building assessment systems involving sustainable building projects, certain specific acoustic aspects are important. In Europe the most common system addressing the problem is the British system Building Research Establishment's Environmental Assessment Method (BREEAM), American system Leadership in Energy and Environmental Design (LEED), or German system Deutsche Gesellschaft fur Nachhaltiges Bauen (DGNB). The green building certificate comprises the assessment of noise impact generated by technical equipment of buildings on their external surroundings. The measures undertaken to counteract noise-generated pollution involve green certification, but it is also a global challenge to find appropriate technological solutions contributing to the protection of areas inhabited by people. We determined the impact of the surroundings of the assessed building in specific background noise conditions. We described the problem of appropriate selection of measurement points and the impact of noise generated by building installations on the acoustic assessment of green buildings in BREEAM system. A theoretical model of the simulated house was developed close to a road, with changes to traffic parameters including heavy vehicles and the summary acoustic power of the equipment mounted on the roof of the investigated house. We analysed the impact involving the location of the investigated building on the possibility to obtain 'credits' in view of environmental acoustics. Instead of a single case study, we used simulation to illustrate different situations such as the changing acoustic background represented by the existing traffic system or changing noise of the sources represented by noise generating units.
\end{abstract}

\section{INTRODUCTION}

In many countries the ecological assessment systems of buildings have become an indispensable element to be taken into account during the construction of office complexes. Such an approach has been enforced by the reduction of energy consumption in the building construction sector which accounts for $40 \%$ of global energy use. Such assessments are closely related with sustainable building construction. Nowadays, it is commonly accepted that sustainable building construction is based on three aspects: environmental, social and economic. $^{1,2}$ Many publications describe most popular assessment systems of green buildings. ${ }^{3-5}$ The present publication focuses on acoustic parameters in view of the Building Research Establishment's Environmental Assessment Method (BREEAM) and the Leadership in Energy and Environmental Design (LEED) assessments.

The BREEAM method was developed in $2011^{6}$ and is the most widely acknowledged scheme, applied to investigate over 2000 buildings in Great Britain. ${ }^{3}$ The key criteria and features of BREEAM Offices are structured hierarchically into Issues, Categories, and Criteria levels. At the top level, there are ten distinct issues (the maximum number of obtainable credits is shown in parentheses): Management (22), Health \& Wellbeing (14), Energy (30), Transport (9), Water (9), Materials (12), Waste (7), Land Use \& Ecology (12), Pollution (13), and Innovation (10). ${ }^{3}$ Acoustic issues are investigated in Health \& Well-being (room acoustics and insulation acoustics) and in Pollution (environmental acoustics). In the BREEAM assessment, a scoring system of particular credits is applied. The awarded credits are summed in a way that ensures an overall scoring for each category is obtained. Then the overall result as well as a percentage of the maximum achievable score for all categories are obtained. The latter is used to determine the overall grade of the assessment, which may be: Pass $(\geq 30 \%)$, Good $(\geq 45 \%)$, Very Good $(\geq 55 \%)$, Excellent $(\geq 70 \%)$ or Outstanding $(\geq 85 \%)$. To obtain BREEAM certification, in addition to achieving a total percentage score that equals or exceeds the minimum percentage score of an awardable grade, a minimum number of credits (defined for each category of assessment pertaining to each rating level) and the number of credits obtained in individual categories must not be lower than the minimum number of credits specified for a given category. ${ }^{3}$

The second important assessment system is the American LEED. The LEED system, designed in 2009, is divided into two levels, categories and points, which is similar to Issues and Categories in other schemes. The system consists of seven categories: Sustainable Sites (26), Water Efficiency (10), Energy and Atmosphere (35), Materials and Resources (14), Indoor Environmental Quality (15), Innovation in Design (6), and Regional Priority (4). The maximum possible total score is 110 points. The awarded points for individual aspects of assessment are summed and compared against a rating scale to yield an overall grade, which may be LEED certified with (4049 points), LEED silver with (50-59 points), LEED gold with (60-79 points) or LEED platinum with ( $>80$ points). As a condition for earning a standard LEED certification, the applicant project must satisfy all prerequisites and score the minimum number of points, i.e., $40-49 .^{3}$

As indicated in many research studies, when carrying out the assessment of green buildings, we should take into account local context, which depends on the geographical location of a country and its economic situation. ${ }^{7-10}$ The local context allows each country to define the parameters of such an assessment in a different way. We can refer here to Seinre et al.'s analysis of BREEAM and LEED requirements in terms of the binding building construction regulations in Estonia. ${ }^{11}$ The 
certification of environmental performance leads to so called Green Buildings which, as described by Wei et al., refer to the structures created with the use of the principles and methodology of sustainable development. ${ }^{12,13}$ Many research studies have been published discussing the 'fitting' of environmental certification systems to the real impact exerted by a building on the environment. Such a problem was investigated by Schweber and Haroglu, where the authors examine the deviations of such 'fittings' from the real impact exerted on the environment using the BREEAM assessment. ${ }^{14}$ It can be observed that the integration of the interdisciplinary project team is of great significance as indicated in Ozorhorn's research. ${ }^{15}$

As indicated in Berardi's works, different assessment systems reflect different approaches to building assessment; therefore, as Berardi claims, a universal assessment category named Sustainable Building Alliance was created. ${ }^{16,17}$

In literature worldwide there are hardly any works describing the impact of an external acoustic climate on a green house certification. One of the very few examples is Costello and Roy's paper, in which the authors analyse and compare the LEED and BREEAM assessment systems in terms of acoustic conditions. ${ }^{18}$ In the same way, Kwok analyses acoustic aspects using the most popular and known worldwide assessment systems of green buildings. ${ }^{19}$ The assessment systems of green buildings take into account the acoustic climate inside buildings. $^{20}$ Indisputably, the acoustic climate inside building structures is affected by reverberation parameters of rooms, sound level in the immediate vicinity of the building elevation, and acoustic insulation of the external building envelopes. ${ }^{21,22}$ Gramez and Boubenider state that an appropriate acoustic climate should be planned at the designing stage of the building. ${ }^{23}$ Such an approach is consistent with the idea of environmental certification, which is also taken into account as early as at the designing stage. In several other works authors observe that the unsatisfactory acoustics of the building are impacted due to oversight the problem at the planning stage of the project. ${ }^{24,25}$ The environmental aspect is referred to by Cole who presents the context of building acoustics in the process of green practices and discusses the direct consequences of the impact exerted by a building project on the environment. ${ }^{26}$

The LEED assessment system is focused principally on the aspects of building assessment in terms of global warming and the reduction of energy consumption. With respect to the reduction of environmental impact, the American assessment system LEED takes no notice of the issues of acoustic climate in the environment, including the impact of near and far climate change after the building is put into operation. However, this system does not leave out the acoustic comfort of the environment inside the building. The BREEAM certification system is based on the British norms involving the requirements of acoustic properties of space, both the internal and external. Noise pollution is included in the category POL - Pollution, which gives a maximum of 12 points in the assessment. As we can see, noise pollution is ranked relatively low in the global assessment of the BREEAM certificate. Yet, the possibility to obtain points with respect to the above depends on the location of the building in the environment. The issue of noise level determination discussed by Morillas et al. defined how people can be affected by traffic noise occurring on the building elevation. ${ }^{27}$ In "Pol 05 Reduction of noise pollution", we can read that the difference of noise level generated by technical facilities of the building, measured at the place of the high- est noise impact and allowing for the existing acoustic background, should not be higher than $5 \mathrm{~dB}$ during daytime and $3 \mathrm{~dB}$ during night time. ${ }^{28} 28 \mathrm{We}$ can see here that we have to face the problem of building location with respect to the noise background, e.g., traffic noise, and the problem involving the selection of measurement points as the places affected by noise the most. The impact of external noise on people staying inside the buildings was investigated by Pirrera et al. ${ }^{29}$ In practice, to analyse noise level, appropriate computer simulations are frequently applied to model the existing traffic system and mutual positioning of the existing buildings, small architecture objects, and installed acoustic protection facilities. ${ }^{30-32}$

Taking into account all the problems described above, the authors of the present work attempt to analyse the impact of the environmental noise on the acquisition of the final score involving the category Pol 05 and to analyse the places exposed to noise in order to identify the ones which are exposed to noise impact the most.

The work undertaken by the authors of the present paper was instigated principally by the fact that there are no clear criteria in the BREEAM procedure for the selection of measurement points which, ultimately, influence the assessment. Since there are no physical means to ensure in the real environment all possible variants that would yield comprehensive and exhaustive conclusions, all the analyses were carried out with the use of computer simulations, taking into account virtual positioning of the buildings.

In the present paper the authors are not investigating the social or economic conditions; as Berardi points out in his publications the assessment systems of green buildings have only recently taken into account the aspects of local residents or the impact of sustainable development on local communities. ${ }^{17}$

\section{MODELLING OF ENVIRONMENTAL NOISE}

The impact of communication systems and buildings fitted with various installations generating noise on the acoustic climate of the environment can be investigated using simulation calculations compiled from an existing numerical model of the terrain (obtained from geodesic records) and the numerical models involving the building sites being planned or being reconstructed. The worked out elevation model should consist of a spatial model of terrain surface (elevation points and edge lines), reflecting (paved) surfaces, and absorbing (unpaved) surfaces, as well as other surface or volumetric elements relevant for the propagation of noise - in this case: roads, existing buildings, tall greenery, embankments, and acoustic screens. The particular constituents of the numerical model of the terrain prepared for the analysis make up a compact surface, covering the total area subject to analysis. The modelling is applied to different sources of noise; in most cases, traffic noise and industrial noise are modelled. The model of traffic source NMPB was described in the French national calculation method NMPB-Routes - 96 (SETRA-CERTU-LCPCCSTB) and in the French Standard - in compliance with the Appendix II directive involving the assessment and management of noise level in the environment. ${ }^{33-35}$ The realization of acoustic maps has been discussed in a paper by Marciniuk et. al. ${ }^{36}$ As the input data, this method applies the emission values from "Guide du bruit des transports terrestres, fascicule prévision des niveaux sonores, CETUR 1980”. The emissions 
described in the method allow for different states of traffic, both with smooth traffic and with accelerations or slowdowns (see Fig. 1). The emission of noise is calculated from:

$$
E=\left(L_{W}-10 \log V-50\right)
$$

where $V$ is the speed of the vehicle $\left[\frac{\mathrm{km}}{\mathrm{h}}\right]$.

The level of acoustic power $L_{W}$ and the emission of sound $E$ are calculated depending on the level of acoustic pressure $L_{P}$ and the vehicle speed $V$, using:

$$
L_{W}=L_{P}+25 \text {. }
$$

"Guide du brutt 1980" contains the nomographs presenting the value of sound level $L_{A e q}$ for one hour in $\mathrm{dB}(\mathrm{A})$, separately defining the emission for light vehicles (sound emission $E_{l v}$ ) and for heavy vehicles (sound emission $E_{h v}$ ) per hour. For these two vehicle categories, $E$ is the function of speed, traffic congestion, and road slope.

The level of acoustic power $L_{A W i}$ of the elementary source is calculated from the relation:

$$
\begin{aligned}
& L_{A W i}=\left[( E _ { V L } + 1 0 \operatorname { l o g } Q _ { V L } ) \oplus \left(E_{P L}+;\right.\right. \\
& \left.\left.+10 \log Q_{P L}\right)\right]+20+10 \log \left(l_{i}\right)+R_{(j)} d B ;
\end{aligned}
$$

where, using the European norm definitions,

$\oplus$ is a symbol used for adding up the levels of sound;

$E_{V L}$ is the sound level defined for light vehicles;

$E_{P L}$ is the sound level defined for heavy vehicles;

$Q_{V L}$ is the hourly flow of light vehicles for a given time period;

$Q_{P L}$ is the hourly flow of heavy vehicles for a given time period;

$l_{j}$ is the length of the section of linear source; representing a single point source; and

$R_{(j)}$ is the spectrum of traffic noise A.

The model describing the sources of industrial character is included in the norm. ${ }^{38}$ In that model the noise sources are characterized by the parameter of acoustic power level $L_{W}$ expressed in $\mathrm{dB}$. The level of acoustic power is the basic quantity which characterizes the emission of noise from its source; hence, it is used to assess the noise generated by the facilities mounted on the roof or on the elevation of the building structure. Equation (4) describes the acquisition method of the equivalent sound pressure level at the reception point:

$$
L_{f T}(D W)=L_{W}+D_{c}-A
$$

where

$L_{f T}$ is the equivalent sound pressure level, $\mathrm{dB}$;

$L_{W}$ is the level of acoustic power of a single point source, $\mathrm{dB}$; $D_{c}$ is a correction resulting from the directivity of sound source, $\mathrm{dB}$; and

$A$ is the sound attenuation, taking place during the propagation of sound source to the reception point, $\mathrm{dB}$.

\section{GEOMETRIC ACOUSTIC MODEL}

The acoustic simulations presenting the distribution of noise level in the vicinity of the preset urban layout were carried out with the use of the calculation package SoundPlan 7.4. The current version of the software applied in the calculations computes the impact of traffic noise in line with the model NMPB



Figure 1. Nomograph used to determine the level of input noise acc. NMPB. ${ }^{37}$

Routes-96 - a French method, and enables the modelling of the equipment mounted on a building in line with the method recommended by the norm. ${ }^{38}$ The search algorithm of the propagation routes of the acoustic wave between the source and the receiver is based on setting the point, linear, and surface sources of noise.

The calculations were based on the factors which have impact on the generation and propagation of noise in a given area:

1. Operation of road communication routes:

- parameters of the communication system (road geometry, grade line inclination);

- the intensity of traffic (the number of vehicles moving along the homogeneous sections of the planned and existing traffic systems, determined on the basis of the average daily traffic obtained from the traffic forecasts);

- percentage share of heavy vehicles in the traffic flow;

- average speed of the moving vehicles;

- type of road ground and greenery present around;

- the existing building development; and

- the existing acoustic barriers.

2. Operation of industrial sources:

- acoustic power of the sources;

- source location; and

- times in operation.

In order to present the generalized situation on one picture, the following procedure was applied:

a) One, predetermined, geometrical model of the terrain (Fig. 2) was accepted, which reflected many different building localizations. Maintaining the generalization aspect, we investigated objects (Fig. 3) located in the immediate vicinity of the assessed noise sources as well as the ones located further. The studies comprised the buildings screened by other objects as well as those which were not screened. 


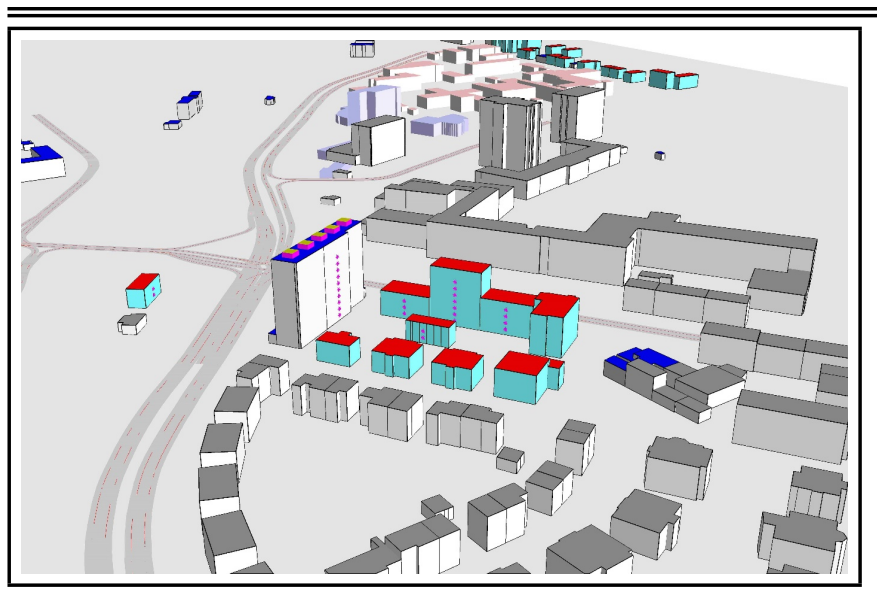

Figure 2. Acoustic-geometric terrain model of the investigated object and its vicinity.

b) The parameters of traffic were changed. The analysis started with the base situation T0 (see Table 1), reflecting the level of acoustic background of residential roads or roads found in housing estates. Then, the share of heavy vehicles was raised, which had impact on the level of acoustic background reaching the parameters of a continuous road.

c) The analyses were carried out for all presented situations. In effect, the generalized model could be investigated.

For the analysis of impact assessment, we accepted the noise generating facilities mounted on the building object BUD_0 (a white building, see Fig. 2) and the vehicles moving along the neighbouring communication arteries. All of these processes were modelled and accordingly ascribed appropriate acoustic and time parameters, depending on the duration of the particular acoustic events. Five air-handling units generating noise were modelled. Each of them had the level of acoustic power of $105 \mathrm{~dB}$, and their maximum loading was modelled over the entire accepted time period of acoustic simulation during daytime and night time.

On the object BUD_0 (see Fig. 2) we successively modelled one, two, three, four and five air-handling units generating noise. The equivalent sound level was analysed on the successive objects BUD_1 - BUD_8, as seen in Fig. 3. On each floor of the investigated objects, two receptors (reception points) were analysed, except for the building BUD_1 on which one receptor which had the highest exposure to noise was selected. The investigated buildings subjected to noise protection had the following heights: BUD_1 had 2 floors, BUD_2 had 3 floors, BUD_3 had 17 floors, BUD_4 had 4 floors, BUD_5 had 2 floors, BUD_6 had 2 floors, BUD_7 had 2 floors, and BUD_8 had 2 floors.

The noise generated by two roads was applied as the acoustic background. Traffic parameters were modelled along the axes of the accepted roads, as presented in Fig. 3.

The model presented in Figs. 2 and 3 was generalized, changing the level of acoustic background. The parameters presented in Table 1 were accepted as the starting point.

In order to differentiate the acoustic background, the percentage share of heavy vehicles in the traffic flow of vehicles was changed. The changes were modelled as the base situation 0 . Then, the share of heavy vehicles per hour was increased, from 80 vehicles to $160,240,320,400,480$, until 560 vehicles per hour. The following denotation was accepted: T0,

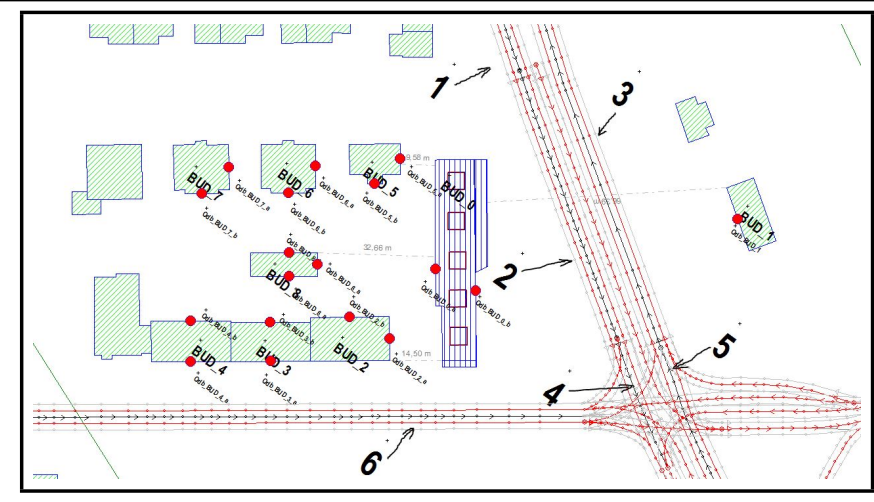

Figure 3. Arrangement plan of receptors on the investigated buildings.

T80, T160, T240, T320, T400, T480, and T560. The analysis comprised all combinations of the generated variants involving the number of switched-on units generating noise and the share of heavy vehicles having impact on the values of acoustic background, which altogether yielded 40 different situations. All the situations were subjected to analysis in 68 calculation points, which yielded 2720 values of sound level in all receptors. The number of the situations is so high that only computer simulation methods can facilitate such an analysis.

\section{RESULTS AND DISCUSSION}

Using the simulation, we first want to obtain information about the places which have 1) the highest exposure to noise under the highest acoustic load generated from the source without the contribution of acoustic background, and 2) about the highest impact of the acoustic background alone, without the contribution of the source. Figure 4 presents the distribution of noise on the particular floors at the measurement points placed on each floor of the building generating noise (BUD_0).

We can see from the graphs presented in Fig. 4 that with the maximum level of acoustic background, its value determines the summary level of sound calculated for BUD_0. Furthermore, the noise at the reception point $R_{b}$ is considerably higher than that at the reception point $R_{a}$.

Similar results were obtained for the buildings located closest to BUD_0 (see Fig. 5). The distances of these buildings from BUD_0 are: BUD_1 located at the distance of $67.90 \mathrm{~m}$, BUD_2 located at the distance of $14.40 \mathrm{~m}$, BUD_5 at the distance of $9.53 \mathrm{~m}$, and BUD_8 at the distance of $32.92 \mathrm{~m}$. The results were presented only for the receptors in which the noise was higher.

Based on the results presented in Fig. 5, we can observe that the highest level of noise emitted by the air-handling unit can be found in the receptors located on BUD_1. It is all the more surprising that the building is located at the longest distance from the sound source. The lowest recorded sound level is on BUD_5, which is quite surprising, since the building is located the closest to the sources of noise generated by technical facilities. Such a distribution of sound levels can be explained by the fact that the building is low and is located in the area of acoustic shadowing. BUD_8 is screened by the remaining buildings from the sources of noise making up the acoustic background; hence, the total equivalent sound level is the lowest of all the investigated cases.

The BREEAM procedure suggested the measurement of the acoustic background at the place most acoustic-sensitive and most exposed to noise, without the acoustic impact of technical 


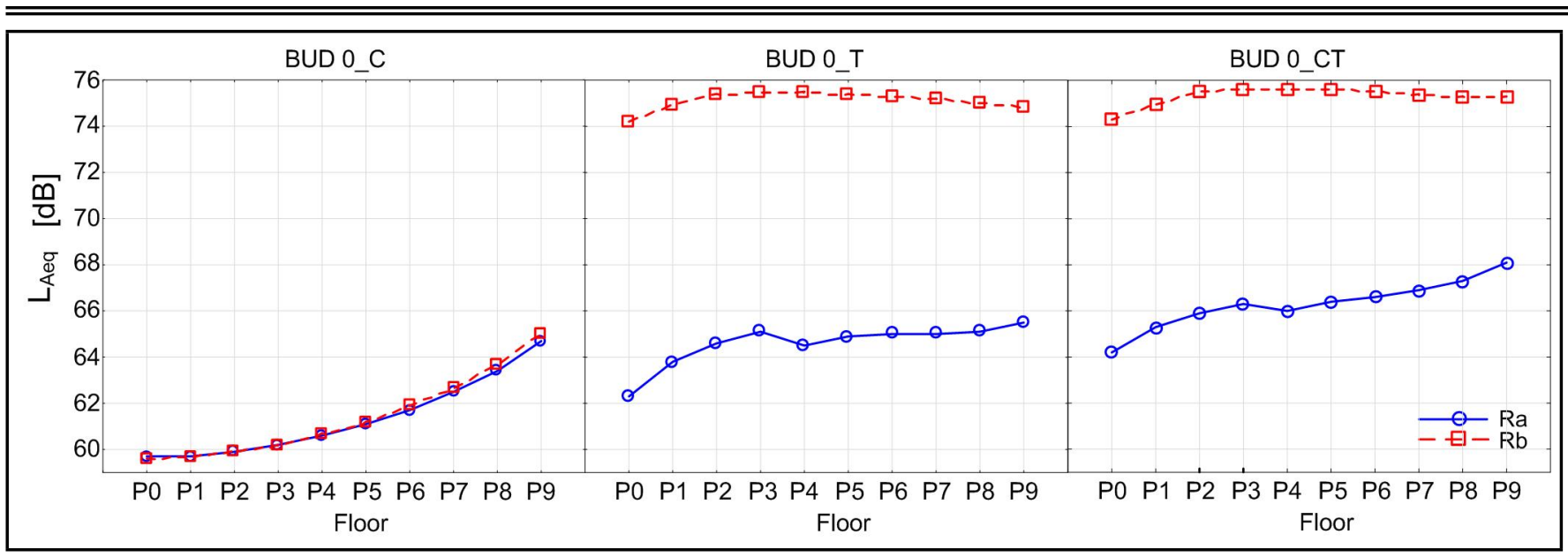

Figure 4. Equivalent level of sound on all floors of the building 0. BUD_0_C shows calculated sound levels of 5 units working simultaneously when the background is switched off; BUD_0_T shows calculated levels of sound generated by the acoustic background when the units are switched off, and BUD_0_CT shows calculated levels of sound with five units working and with the maximum loading of the acoustic background (560 heavy vehicles per $24 \mathrm{~h}$ ).

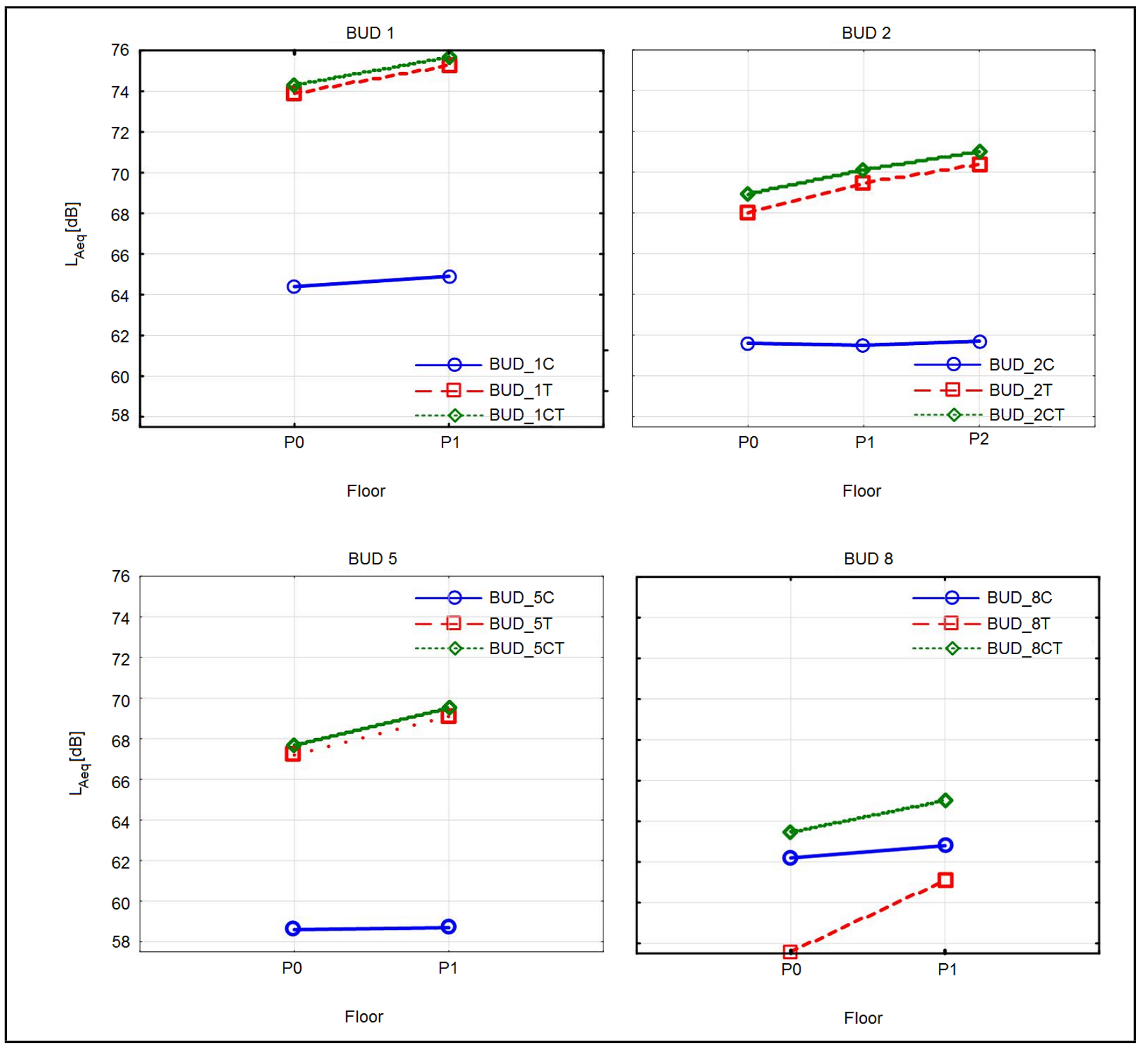

Figure 5. Equivalent level of noise on the floors of the buildings located in the immediate vicinity of BUD_0 (unobstructed ones). X stands for building number, $\mathrm{C}$ demonstrates that only units on object 0 are working, $\mathrm{T}$ is the level of acoustic background with the switched on units, and CT illustrates all units are working and acoustic background from the road is switched on. 
Table 1. Traffic parameters for the base situation T0.

\begin{tabular}{|c|c|c|c|c|c|c|c|c|c|c|c|c|}
\hline & \multicolumn{7}{|c|}{ Vehicles per hour $[\mathrm{veh} / \mathrm{h}]$} & \multicolumn{6}{|c|}{ Percentage share [\%] } \\
\hline Road axis & $\mathbf{1}$ & $\mathbf{2}$ & $\mathbf{3}$ & $\mathbf{4}$ & $\mathbf{5}$ & $\mathbf{6}$ & $\mathbf{1}$ & $\mathbf{2}$ & $\mathbf{3}$ & $\mathbf{4}$ & $\mathbf{5}$ & $\mathbf{6}$ \\
\hline Light veh. & 863 & 708 & 863 & 680 & 604 & 634 & 93.4 & 97.7 & 93.4 & 97.7 & 97.7 & 98.8 \\
\hline Heavy veh. & 61 & 17 & 61 & 16 & 14 & 8 & 6.6 & 2.3 & 6.6 & 2.3 & 2.3 & 1.2 \\
\hline
\end{tabular}

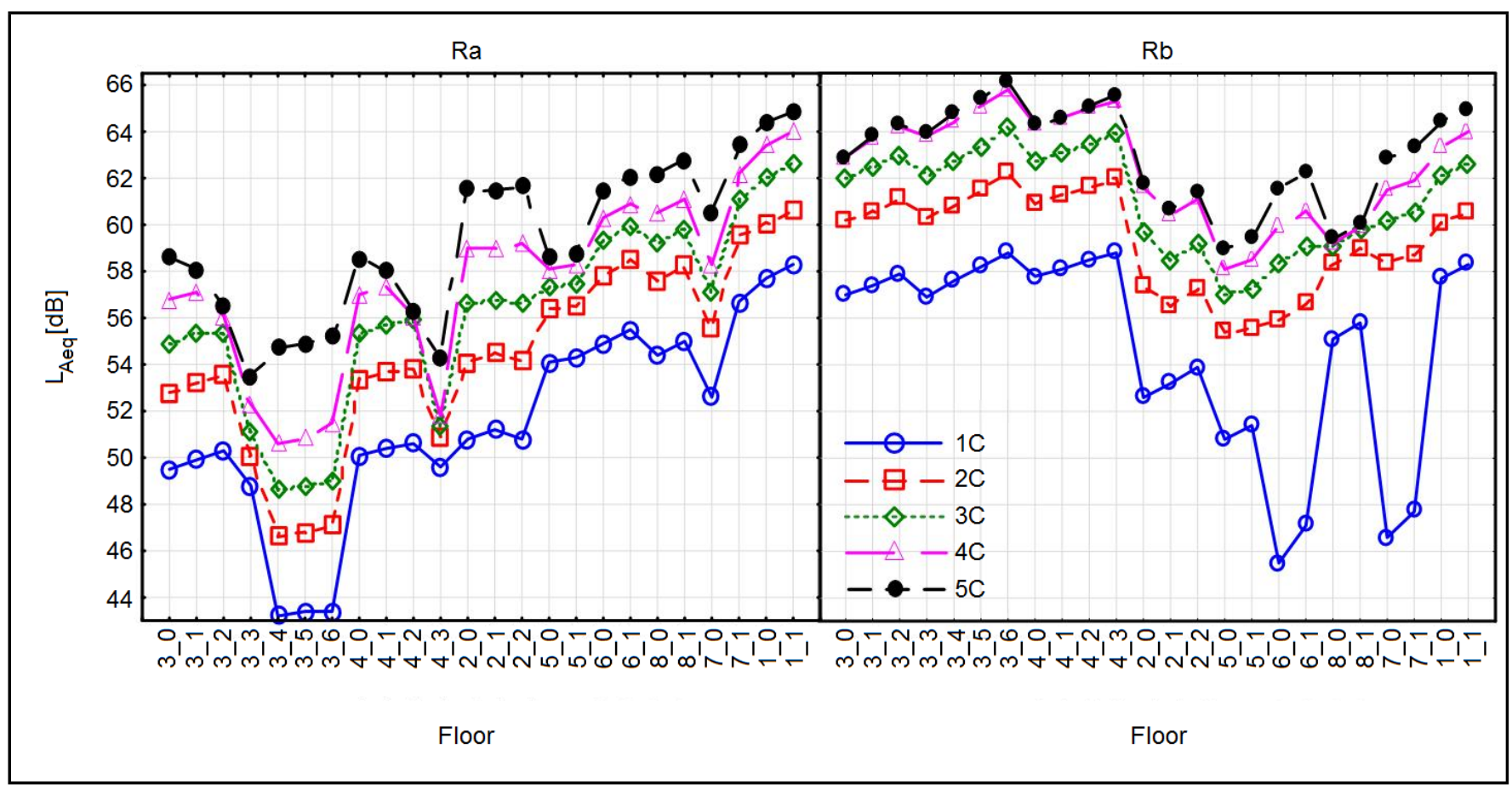

Figure 6. Levels $L_{A e q}$ in all receptors. $R_{a}$ depicts receptors $a$ on the left, $R_{b}$ depicts receptors $b$ on the right. In $n C, n$ refers to the number of switched on units. In $k_{-} P k$ refers to the number of buildings while $P$ refers to the number of floors.

facilities present in the investigated building (if possible), as well as the measurement of the total level of sound emitted by all sources of noise. As we can see, the examples alone demonstrate how important it is to select the measurement points of noise. Without a detailed analysis - preferably with the help of computer simulations - we are not in a position to correctly assess which object subjected to protection is exposed the most to noise impact. It is worthwhile to mention that the highest levels of noise are on higher floors because the impact of traffic system is the only source of acoustic background.

In order to complement the presented analysis, Table 2 shows the results for the remaining objects, which are presented in the form of equivalent noise level. It can be clearly seen that for the buildings BUD_3 and BUD_4, the level of sound from the air-handling units is higher in the receptors placed inside the investigated complex of buildings (see Fig. 3), and for the acoustic background it is outside the complex. Furthermore, we can see that for the receptor $R_{a}$ the level of background is so high that it surpasses the noise generated by the units. It is confirmed by the obtained results of the total noise level, which is close to the level of the acoustic background alone. For the receptor $R_{b}$ the levels of noise generated by air-handling units and by the acoustic background have similar values, and the total level of sound is much higher than each of them separately. In the objects BUD_6 and BUD_7 the situation is reversed.

In the BREEAM in POL 05 reduction of noise procedure we can read the following:

"Criterion 1 - The noise level of a building being designed, measured at the closest place, or at the place with the highest exposure to noise shall not be higher than $+5 \mathrm{~dB}$ during
Table 2. Equivalent sound levels in the receptors $R_{a}$ and $R_{b}$. Denotation: 5C stands for five switched on units; T560 stands for acoustic background with the use of 560 heavy vehicles per hour; and 5C_T560 stands for five turned on units and acoustic background with the use of 560 heavy vehicles per hour.

\begin{tabular}{||c|c|c|c|c|c|c||}
\hline & \multicolumn{2}{|c|}{$5 \mathrm{C}$} & \multicolumn{2}{c|}{ T560 } & \multicolumn{2}{c|}{$5 \mathrm{C}_{-} \mathrm{T} 560$} \\
\hline & $\begin{array}{l}R_{a} \\
(\mathrm{~dB})\end{array}$ & $\begin{array}{l}R_{b} \\
(\mathrm{~dB})\end{array}$ & $\begin{array}{l}R_{a} \\
(\mathrm{~dB})\end{array}$ & $\begin{array}{l}R_{b} \\
(\mathrm{~dB})\end{array}$ & $\begin{array}{l}R_{a} \\
(\mathrm{~dB})\end{array}$ & $\begin{array}{l}R_{b} \\
(\mathrm{~dB})\end{array}$ \\
\hline BUD 3_P0 & 49.5 & 57.0 & 73.1 & 51.0 & 73.2 & 63.2 \\
\hline BUD 3_P1 & 49.9 & 57.4 & 74.0 & 53.3 & 74.1 & 64.1 \\
\hline BUD 3_P2 & 50.3 & 57.9 & 74.1 & 55.3 & 74.2 & 64.8 \\
\hline BUD 3_P3 & 48.8 & 56.9 & 74.1 & 58.3 & 74.1 & 64.9 \\
\hline BUD 3_P4 & 43.2 & 57.6 & 73.9 & 59.5 & 73.9 & 65.9 \\
\hline BUD 3_P5 & 43.4 & 58.2 & 73.6 & 59.7 & 73.7 & 66.4 \\
\hline BUD 3_P6 & 43.4 & 58.8 & 73.4 & 60.0 & 73.4 & 66.9 \\
\hline BUD 4_P0 & 50.1 & 57.8 & 73.0 & 52.6 & 73.2 & 64.6 \\
\hline BUD 4_P1 & 50.4 & 58.1 & 73.8 & 54.8 & 73.9 & 65.0 \\
\hline BUD 4_P2 & 50.6 & 58.5 & 73.9 & 56.5 & 74.0 & 65.6 \\
\hline BUD 4_P3 & 49.6 & 58.8 & 73.8 & 58.1 & 73.9 & 66.1 \\
\hline BUD 6_P0 & 54.9 & 45.5 & 58.8 & 54.4 & 63.4 & 62.3 \\
\hline BUD 6_P1 & 55.5 & 47.1 & 62.9 & 57.5 & 65.6 & 63.4 \\
\hline BUD7_P0 & 52.6 & 46.6 & 53.5 & 51.3 & 61.3 & 63.1 \\
\hline BUD 7_P1 & 56.7 & 47.7 & 57.5 & 54.1 & 64.3 & 63.8 \\
\hline
\end{tabular}

the daytime as compared to the acoustic background, and not higher than $+3 \mathrm{~dB}$ during the night time."

The above provision raises some doubts. First, we have already expressed some doubts mentioned before involving the place with the highest exposure to noise (it does not have to be the closest locality). Second, the question is whether we can by any means satisfy the criterion with the difference being less than $+5 \mathrm{~dB}$ during daytime and $+3 \mathrm{~dB}$ during the night time. In order to verify the said criterion, further computer tests were carried out.

In Fig. 6 we present two graphs. Graph 6 a presents the equivalent levels of sound in receptor $R_{a}$ with different acous- 


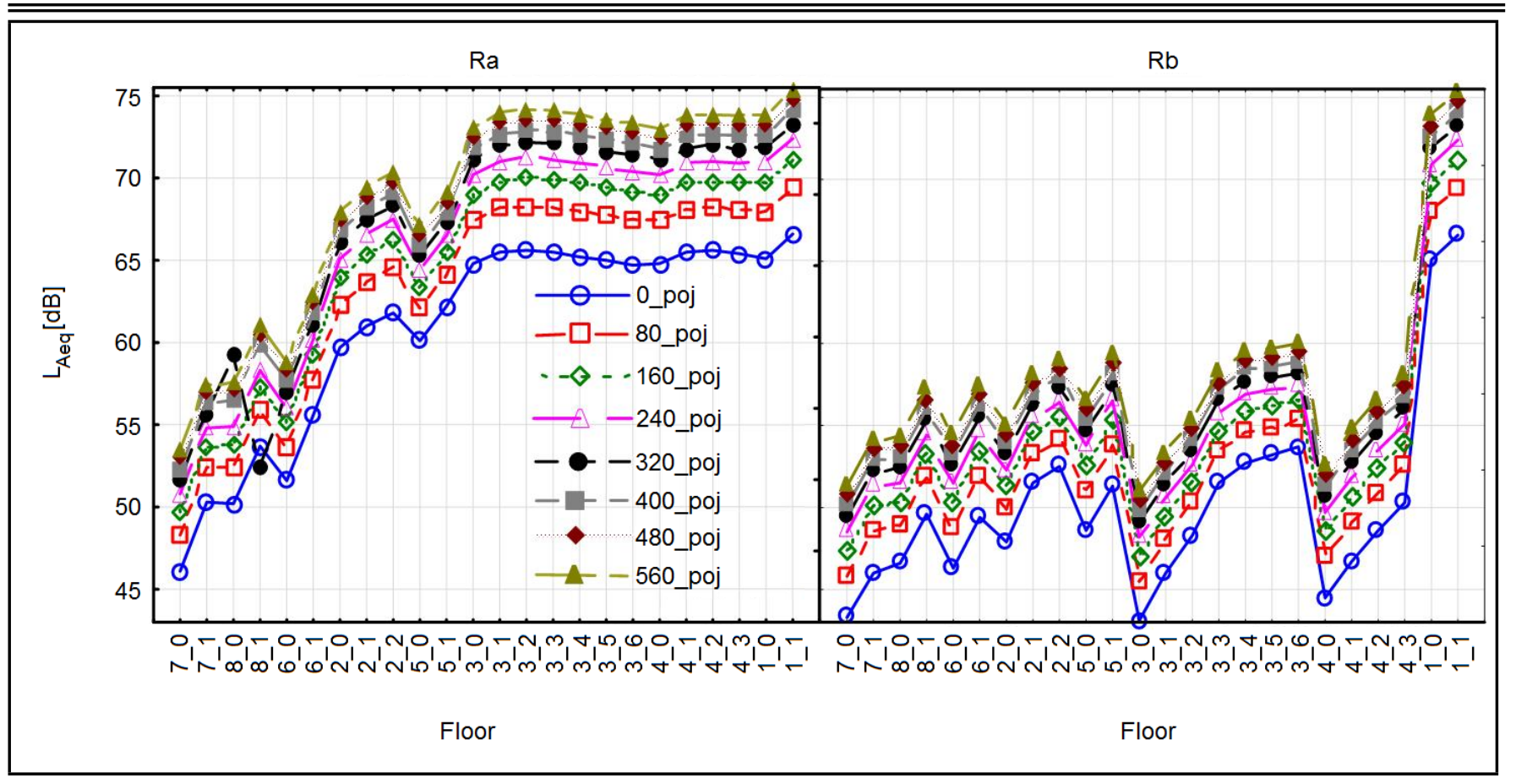

Figure 7. Levels $L_{A e q}$ of the acoustic background in all receptors. $R_{a}$ on the left and $R_{b}$ on the right.

tic load generated by the units mounted on the roof of BUD_0 with a switched off acoustic background. Graph $6 \mathrm{~b}$ shows the equivalent levels of sound in receptor $R_{b}$ with different acoustic load generated by the air-handling units mounted on the roof of BUD_0, not taking into account the acoustic background.

The graphs in Fig. 6 clearly demonstrate a paradox that shows that for the building located the farthest from the sound source, the levels are the highest. It can only be explained by the fact that the sound source is located at a great height, and therefore all buildings located closer are in a so-called acoustic shadowing.

The acoustic background is substantially higher at the measurement points $R_{a}$, and the noise generated by the airhandling units is slightly higher at points $R_{b}$ (Fig.7).

The last analysis presented in this work involves the verification of Criterion 1, i.e., the differences between the level of noise generated by the air-handling units mounted on BUD_0 and levels generated by the existing acoustic background.

On the graphs presented in Fig. 8, the continuous line in bold represents the difference between the noise generated by the preset noise sources and the acoustic background, which was $+5 \mathrm{~dB}$. The broken line stands for the same difference at the level of $+3 \mathrm{~dB}$. Based on the analysis of the results presented in Fig. 8, we can state that with respect to the investigated system, it is difficult to satisfy the requirement provided in Criterion 1, even in the case when only one unit is making noise. Hence, for BUD_7 (the lowest noise emission), the preset acoustic standards were surpassed in receptor $R_{a}$. With respect to receptor $R_{b}$, such standards are also surpassed in most of the buildings. It is probably caused by the fact that these places are characterized by low level of acoustic background, which makes the level of that difference too high. The conclusions drawn from the analysis of Fig. 5 can be confirmed by the analysis of noise maps calculated at particular heights, as presented in Fig. 9.

The cross-sections presented in Fig. 9 confirm that depending on the geometry of the system, the impact of excessive noise can apply to buildings both smaller and located at further distance from the investigated noise source.

We can discern the difference in acoustic background levels, depending both on the depth of urban interior and on the floor at which excessive noise levels are analysed. Ultimately, the distribution of noise levels is dependent on the impact of technical equipment installed on the assessed object and on other building objects which function as screening elements.

\section{SUMMARY}

The environmental acoustics as one of the aspects of the assessment of green houses are frequently underestimated. If by any chance it is taken into account, the approach to this issue is not always clear and correct. The permissible levels of noise generated either by traffic or industrial installations are defined in various regulations for each individual country. Although the entry Criterion 1 in the BREEAM procedure consists of one complex sentence, it can bring about several unclear interpretations and misunderstandings. Therefore, the present paper investigates the distribution of sound levels in a simulated environment based on a real project in which BUD_0 is simulated. In the performed research studies, the parameters of noise sources (air-handling units) and the parameters of acoustic background were purposefully selected to ensure the acquisition of (possibly) the broadest gamut of results for analysis. The levels of sounds generated by the source and recorded at the measurement points were changing within the range of $\langle 42.1 \mathrm{~dB} ; 66.1 \mathrm{~dB}\rangle$, and the variability of the acoustic background was within the range of $\langle 43.1 \mathrm{~dB} ; 75.5 \mathrm{~dB}\rangle$. Such a broad gamut of variations allowed the authors to analyse 2720 cases of calculation results in the preset receptors.

The present paper is not investigating the problems separately for road infrastructure or a housing estate. The analysis was not carried out in the same manner as Sharifi and $\mathrm{Mu}-$ rayama's work, limiting the assessment to the local level. ${ }^{4}$ It should be emphasized that the situation analysed in the paper 


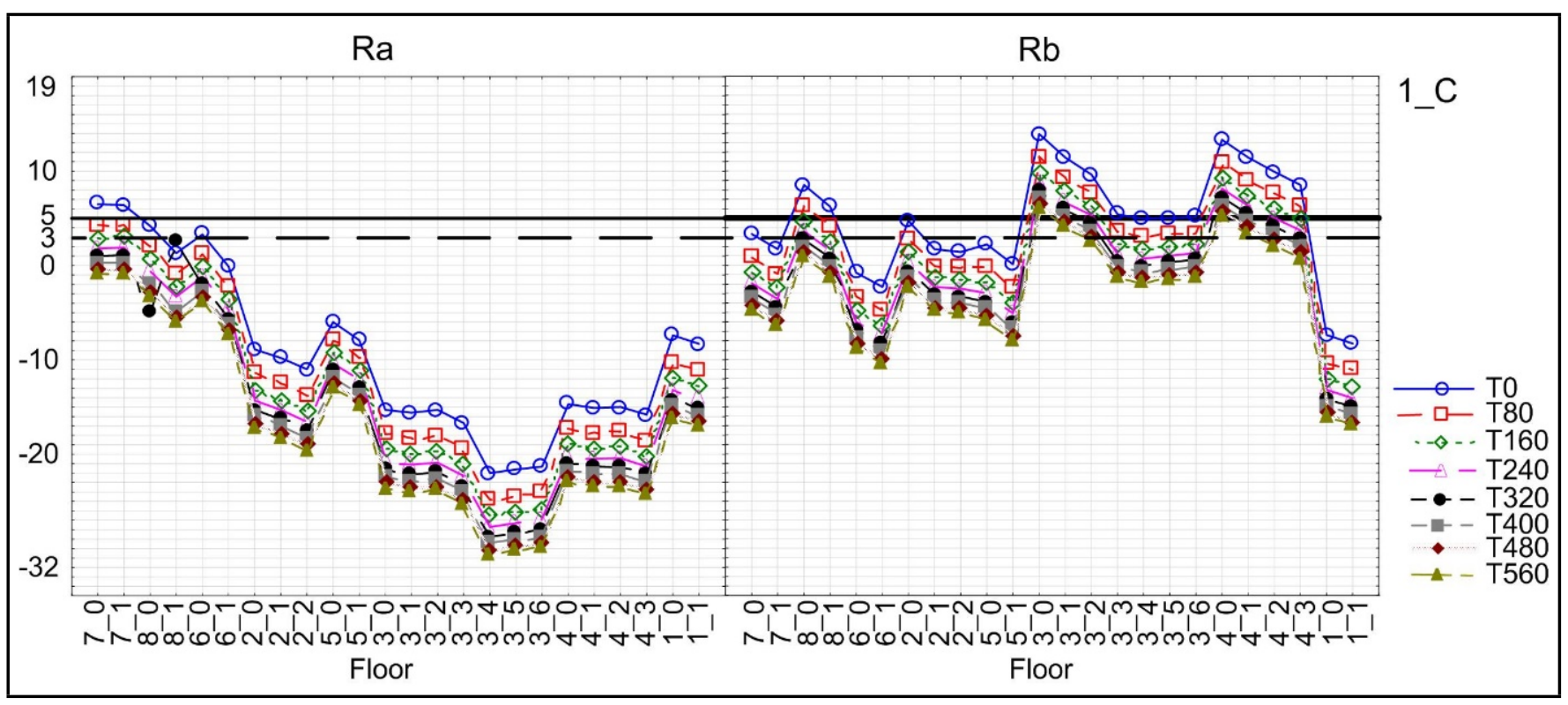

Figure 8. Sound levels, allowing for all combinations of acoustic source load (the units) and acoustic background (the share of heavy vehicles). C_1 is one switched on unit, $2 \mathrm{C}$ is two switched on units, ..., continuing up to $5 \mathrm{C}$ five switched on units. T0 shows no heavy vehicles in the traffic. T80 is the share of 80 heavy vehicles in the traffic, ..., continuing up to T560, the share of 560 heavy vehicles.

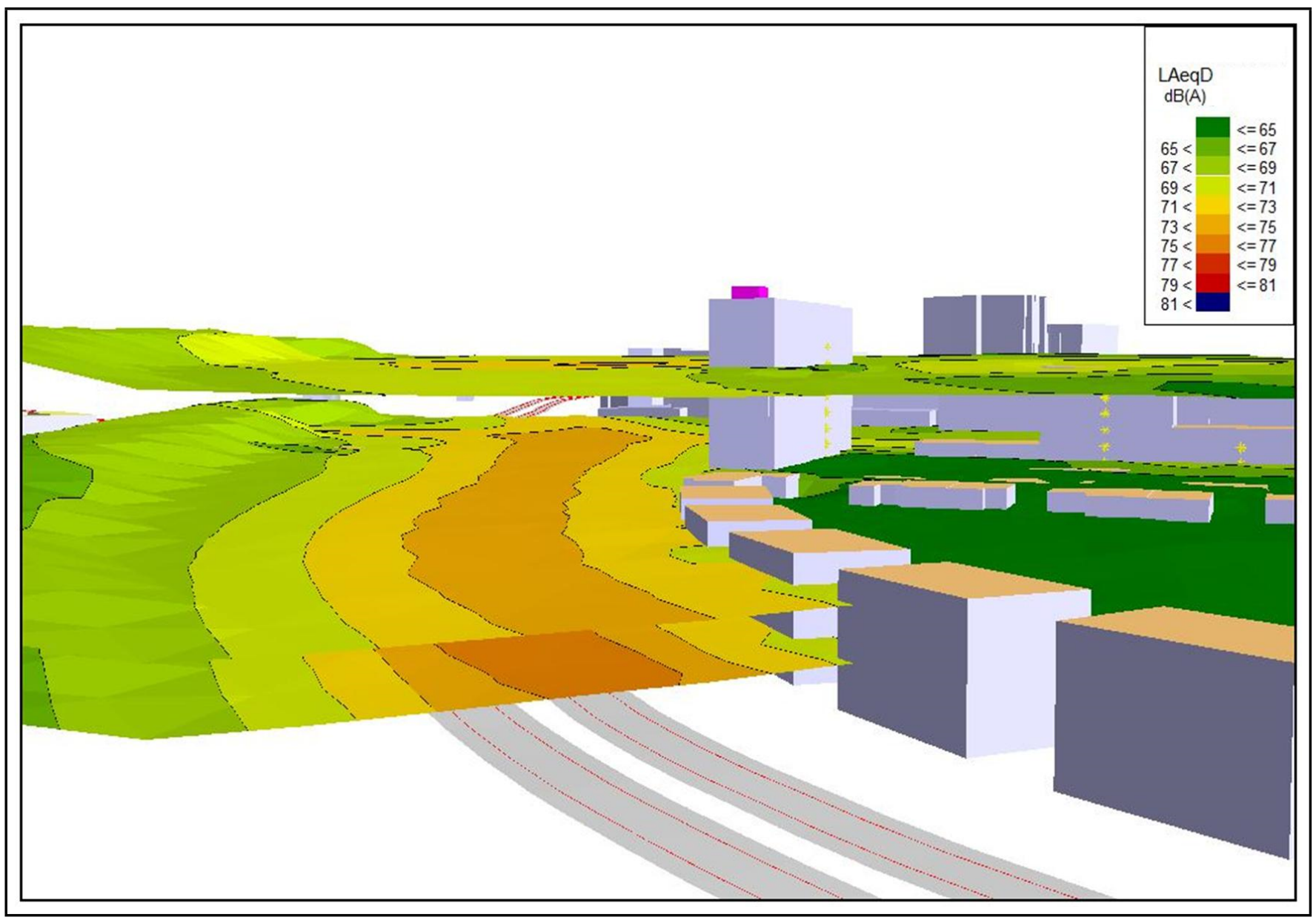

Figure 9. Three cross-sections of noise distribution in the environment when the acoustic background is of T80 type and with one unit located on the roof of BUD0. The first cross-section refers to the height of $4 \mathrm{~m}$ from the ground level, the second to the height of the lowest acoustically-sensitive building, and the third to the height of the highest acoustically-sensitive building. 
refers to the place in the vicinity of the existing road infrastructure. If we investigated the problem from the perspective of a housing estate located at a certain distance from the communication system, then, in terms of acoustics, only the parameters of acoustic background would be different. Therefore, we can state that the situation presented in this paper embraces a wider range of situations. Assuming the acoustic background at the level within $45-75 \mathrm{~dB}$, as analysed in the paper, we can accept that the analysis also involves housing estate roads. When we accept higher levels of acoustic background, we acknowledge that the situation is changing towards the location with road infrastructure.

The following conclusions can be drawn from that analysis:

a) The selection of measurement points is very significant, and ultimately has an impact on the final assessment result of the investigated building. The choice of the closest place does not necessarily imply the highest exposure to noise. Moveover, most frequently, the higher building floors are exposed to noise, standing in opposition to the common practice of carrying out the measurements only at the height of $4 \mathrm{~m}$ above the ground. It is important that the designing stage of a building should comprise the distribution analysis of sound levels in the whole environment surrounding the planned object.

b) Depending on the geometry of the whole investigated layout, we may witness a situation where the building located the farthest from the sound source has the highest exposure to noise. The distribution of sound levels for the situation most beneficial for the environment - i.e., for one working air-handling unit and the level of acoustic background of T80 - is presented on the maps in Fig. 9.

c) The difference of $+5 \mathrm{~dB}$ by day and $+3 \mathrm{~dB}$ by night required for a positive assessment between the sound level generated by the source and the level of acoustic background may be impossible to achieve. We can venture to say that, having taken into account all the situations presented in this paper and having investigated the distribution of noise in the whole environment, we would certainly be able to find places outside the standard measurements where the above limits are surpassed.

d) The assessment, due to the introduction of noise to the environment, is a component of the Pollution criterion in the BREEAM assessment. For the entire Pollution criterion we can attain merely 13 credits out of 132, which accounts for about $10 \%$. Taking into account the fact that the noise stands for 1 credit, we can accept that in terms of the present assessment the lack of one credit is rather insignificant. Therefore, in terms of BREEAM assessment, conclusion 3 cannot weigh on the whole assessment. Yet, taking into account life comfort and health aspects, all analyses contributing to the reduction of noise in the environment are of great significance today.

It is worth pointing out that the assessed building investigated in the paper was a high office building. The situation can be entirely different for buildings occupied by educational establishments, administration offices, or shopping galleries. It would also be interesting to carry out an acoustic analysis of the interiors of the investigated buildings involving the insulation of building envelopes, or the reception of speech sounds.
Such issues have not been referred to in the present paper, and they will be developed by the authors in further research studies.

\section{ACKNOWLEDGEMENT}

Publication supported is a part of the postdoctoral habilitation grant. Silesian University of Technology, no. 03/030/RGH17/0055.

\section{REFERENCES}

1 Cole, R.J. Building environmental assessment methods; redefining intentions and roles. Building Research \& Information, 33 (5), 455-467, (2005). https://dx.doi.org/10.1080/09613210500219063

2 Zuo, J. and Zhao, Z. Y. Green building research - current status and future agenda: a review. Renewable and sustainable energy reviews, 30, 271-281, (2014). https://dx.doi.org/10.1016/j.rser.2013.10.021

3 Lee, W. L. A comprehensive review of metrics of building environmental assessment schemes, Energy and Buildings, 62, 403-413, (2013). https://dx.doi.org/10.1016/j.enbuild.2013.03.014

4 Sharifi, A. and Murayama, A. A critical review of seven selected neighborhood sustainability assessment tools. Environmental Impact Assessment Review, 38, 73-87, (2013). https://dx.doi.org/10.1016/j.eiar.2012.06.006

5 Mattoni, B., Guattari, G., Evangelisti, L., Bisegna, F., Gori, P. and Asdrubali F. Critical review and methodological approach to evaluate the differences among international green building rating tools. Renewable and Sustainable Energy Reviews, 82, 950-960, (2018). https://dx.doi.org/10.1016/j.rser.2017.09.105

6 BREEAM, BREEAM New Construction Technical Manual 2011, BRE Global, (2012).

7 Lee, W. L. and Burnett, J. Customization of GBTool in Hong Kong. Building and Environment, $41 \quad$ (12), 1831-1846, (2006). https://dx.doi.org/10.1016/j.buildenv.2005.06.019

8 Ali, H. H. and Al. Nsairat, S. F. Developing a green building assessment tool for developing countries - case of Jordan. Building and Environment, 44 (5),1053-1064, (2009). https://dx.doi.org/10.1016/j.buildenv.2008.07.015

9 Wallhagen, M., Glaumann, M. and Malmqvist, T. Basic building life cycle calculations to decrease contribution to climate change - case study on an office building in Sweden. Building and Environment, 46 (10), 1863-1871, (2011). https://dx.doi.org/10.1016/j.buildenv.2011.02.003

10 Alyami, S. H., Rezgui, Y. and Kwan, A. Developing sustainable building assessment scheme for Saudi Arabia: Delphi consultation approach. Renewable and sustainable energy reviews, 27, 43-54, (2013). https://dx.doi.org/10.1016/j.rser.2013.06.011

11 Seinre, E., Kurnitski, J. and Voll H. Building sustainability objective assessment in Estonia context and a comparative evaluation with LEED and BREEAM. 
Building and Environment, 82, 110-120, (2014). https://dx.doi.org/10.1016/j.buildenv.2014.08.005

12 Wei, W., Ramalho, O. and Mandin, C. Indoor air quality requirements in green building certifications. Building and Environment, 92, 10-19, (2015). https://dx.doi.org/10.1016/j.buildenv.2015.03.035

13 Kibert, C. J. Sustainable construction: green building design and delivery. 3rd ed, John Wiley \& Sons, Inc., (2012).

14 Schweber, L. and Haroglu, H. Comparing the fit between BREEAM assessment and design processes. Building Research \& Information, 42 (3), 300-317, (2014). https://dx.doi.org/10.1080/09613218.2014.889490

15 Ozorhorn, B. Analysis of construction innovation process at project level. Journal of management in engineering, 29 (4), 455-463, (2013). https://dx.doi.org/10.1061/(ASCE)ME.19435479.0000157

16 Berardi, U. Sustainability assessments of buildings, communities, and cities, in Klemeš J.J (Editor). Assessing and Measuring. Environmental Impact and Sustainability, 497545 Elsevier, Oxford, (2015).

17 Berardi, U. Sustainability Assessment in the Construction Sector: Rating Systems and Rated Buildings. Sustainable Development, 20 (6), 411-424, (2012). https://dx.doi.org/10.1002/sd.532

18 Costello, A. and Roy, K. Comparing acoustical requirements of green building assessment systems. The Journal of the Acoustical Society of America, 124 (4), 2545, (2008). https://dx.doi.org/10.1121/1.4782976

19 Kwok, M. Acoustic design criteria in green building rating systems. The Journal of the Acoustical Society of America, 131 (4), 3510, (2012). https://dx.doi.org/10.1121/1.4709268

20 Noble, M. R. Green buildings: Implications for acousticians. The Journal of the Acoustical Society of America, 117 (4), 2378, (2005). https://dx.doi.org/10.1121/1.4785632

21 Nowoświat, A. and Olechowska, M. Investigation Studies on the Application of Reverberation Time. Archives of Acoustics, 41 (1), 15-26, (2016). https://dx.doi.org/10.1515/aoa-2016-0002

22 Olechowska, M. and Ślusarek J. Analysis of selected methods used for the reverberation time estimation. Architecture Civil Engineering Environment, 9 (4), 79-87, (2016).

23 Gramez, A. and Boubenider, F. Acoustic comfort evaluation for a conference room: A case study. Applied Acoustics, 118, 39-49, (2017). https://dx.doi.org/10.1016/j.apacoust.2016.11.014

24 Knecht, H. A., Nelson, P. B., Whitelaw, G. M. and Lawrence, L. Background noise levels and reverberation times in unoccupied classrooms predictions and measurements. American Journal of Audiology, 11 (2), 65-71, (2002). https://dx.doi.org/10.1044/1059-0889(2002/009)
$25 \mathrm{Wu}, \mathrm{S}$., Peng, J., and Bi, Z. Chinese speech intelligibility in low frequency reverberation and noise in a simulated classroom. Acta Acustica United With Acustica, 100 (6), 10671072, (2014). https://dx.doi.org/10.3813/AAA.918786

26 Cole, R. J. Assessing the future of green building. The Journal of the Acoustical Society of America, 117 (4), 2377, (2005).

27 Morillas, J., González, D. M. and Gozalo, G. R. A review of the measurement procedure of the ISO 1996 standard. Relationship with the European Noise Directive. Science of the Total Environment, 565, 595-606, (2016). https://dx.doi.org/10.1016/j.scitotenv.2016.04.207

28 BREEAM UK New Construction. Non-Domestic Buildings. Technical Manual SD5076: 0.1 (Draft), BRE Global Limited, Watford, (2014).

29 Pirrera, S., De Valck, E. and Cluydts, R. Field study on the impact of nocturnal road traffic noise on sleep: The importance of in- and outdoor noise assessment, the bedroom location and night time noise disturbances. Science of the Total Environment, 500, 84-90, (2014). https://dx.doi.org/10.1016/j.scitotenv.2014.08.061

30 Bastián-Monarca, N. A., Suárez, E. and Arenas, J. P. Assessment of methods for simplified traffic noise mapping of small cities: Casework of the city Valdivia, Chile. Science of the Total Environment, 550, 439-448, (2016). https://dx.doi.org/10.1016/j.scitotenv.2016.01.139

31 Wei, W., Van Renterghem, T., De Coensel, B. and Botteldooren, D. Dynamic noise mapping: A map-based interpolation between noise measurements with high temporal resolution. Applied Acoustics, 101, 127-140, (2016). https://dx.doi.org/10.1016/j.apacoust.2015.08.005

32 Ko, J. H., Chang, S. and Lee, B. Ch. Noise impact assessment by utilizing noise map and GIS: A case study in the city of Chungju, Republic of Korea. Applied Acoustics, 72 (8), 544-550, (2011). https://dx.doi.org/10.1016/j.apacoust.2010.09.002

33 NOR: EMVP9540148A. Arrêté du 5 mai 1995 relatif au bruit des infrastructures routières.

34 French Standard "XPS-31-133”, 2001. Acoustique - Bruit des infrastructures de transport terrestres - Calcul de l'attènuation du son lors de sa propagation en milieu extèrieur, incluant les effets mètèorologiques.

35 DIRECTIVE 2002/49/EC OF THE EUROPEAN PARLIAMENT AND OF THE COUNCIL - relating to the assessment and management of environmental noise.

36 Marciniuk, K., Szczodrak, M. and Kostek, B. Performance of Noise Map Service Working in Cloud Computing Environment. Archives of Acoustics, 41 (2), 297-302, (2016). https://dx.doi.org/10.1515/aoa-2016-0029

37 Lebiedowska, B. Noise Around Motorways. Propagation methods, Łódź, 1988 (in Polish).

38 ISO 9613-2:1996. Acoustics - Attenuation of sound during propagation outdoors - Part 2: General method of calculation. 